\title{
SEDATION ANALGESIA FOR OUT PATIENT LITHOTRIPSY
}

\author{
Olfat M. Ismail, MD* Khaled Z. Sheir, MD** \\ From \\ * Anaesthesia Department - Mansoura University \\ ** Urology \& Nephrology Center - Mansoura University
}

\begin{abstract}
This study was conducted on 40 ASA physical status I-II outpatients who were scheduled for unilateral ESWL to evaluate the safety and efficacy of ketamine versus fentanyl when infused in combination with midazolam for sedation and analgesia. Patients were randomly allocated into two equal groups according to the study drug used ketamine group and fentanyl group. Midazolam 1-3 mg was given to all patients IV to relieve anxiety. Heart rate, systolic and diastolic blood pressure, respiratory rate and oxygen saturation were recorded every 5 min during ESWL procedure. Involuntary movements, respiratory upsets, episodes of desaturation, nausea / vomiting and complaints of pain were also recorded. Although both drug regimens allowed the maximal number of shock waves and energy levels, ketamine infusion provid-
\end{abstract}

ed superior intraoperative cardiorespiratory stability. However it was associated with more disruptive movements during the procedure and longer recovery times. Incidence ofcommon postoperative side effects (nausea, vomiting, dizziness, confusion) did not differ significantly between the two groups. From the results of the study we can conclude that lithotripsy can be satisfactorily performed by employing ketamine infusion in combination with midazolam for sedation and analgesia.

\section{INTRODUCTION}

Extracorporeal shockwave lithotripsy (ESWL) for the treatment of kidney and ureteral stones is today a highly popular and widely used alternative to percutaneous nephrolithotomy and surgical removal of urinary stones. Its advantages include a high success rate, low morbidity, shorter

MANSOURA MEDICAL JOURNAL 
hospital stay and lower cost $(1,2)$. Because ESWL produces painful stimuli general or regional anesthesia is required to prevent not only pain but also movement by the patient that might alter the position of a stone targeted on the image intensifier screen (3). Newer genertion machines are purportedly less painful and may be amenable to monitored anesthesia care (4). In Mansoura Urology and Nephrology Center a secondgeneration lithotriptor is used. This lithotriptor lessens patient discomfort by delivering less power than the first generation machines, and providing a narrow area through which the shock waves enter the body. Modern lithotriptors are quicker but still require analgesia. Intravenous opioids are currently the drugs in favor for less painful lithotripsy procedures performed under monitored anesthesia care (5). Use of intravenous sedative analgesic techniques can provide adequate analgesia with shorter recovery times when used. Ketamine's ability to produce sedation analgesia without clinically significant ventilatory depression might offer an advantage over techniques involving the use of opioid analgesic infusions (6).

The aim of this study is to com- pare the clinical efficacy and safety of ketamine versus fentanyl when infused in combination with midazolam during lithotripsy. We assessed recovery times, postoperative side effects and therapeutic outcome when these two IV sedative analgesic techniques were used for outpatient lithotripsy.

\section{MATERIALS \& METHODS}

Forty ASA physical status I-II adult outpatients scheduled for ESWL procedures were randomly assigned to receive ketamine or fentanyl as IV sedative analgesic according to a double blind protocol. The local Ethical Committee approved the protocol and informed consent was obtained from the patients. All patients selected for the treatment were carefully evaluated by the urologist and the anesthesiologist including ECG, intravenous pyelogram, renal tomograms, and careful medical history. Exclusion criteria were patients with pain prior to treatment; patients treated with a spasmolytic-or analgesic drug or those with a history of allergy to any of the study medications. Both treatment groups were given 1-3 mg midazolam IV to relieve anxiety. Baseline measurement of non-invasive blood pressure, heart rate, respiratory rate and arterial oxygen saturation were 
recorded. Most of the patients were treated in supine position. In ketamine group (K) sedation was initiated with ketamine $0.5 \mathrm{mg} \mathrm{kg}-1$ followed by an infusion of ketamine $1 \mathrm{mg} / \mathrm{ml}$ at vriable rate of $1-10 \mathrm{ml} / \mathrm{min}$. In fentanyl group ( $F)$ sedation was induced with I ug kg-1 fentanyl followed by $2 \mathrm{ug} / \mathrm{ml}$ at a variable rate of $1.10 \mathrm{mV} / \mathrm{min}$. The signs of adequate analgesia that dictated the need for increasing the infusion rate were identical in the two treatment groups and included patient movement, lacrimation, or diaphoresis or a progressive increase in respiratory rate, heart rate, or mean arterial blood pressure exceeding $20 \%$ of the values that prevailed at the conclusion of the induction sequence. Additional midazolam $0.5 \mathrm{mg}$ IV bolus dose was given where the patient appeared restless or exhibited excessive movement (which interfered with the surgeon's ability to focus on the renal stone), or if the patient complained of pain in response to the stimulus and did not respond to increases in the maintenance infusion rate of the study drug. In the absence of signs of inadequate analgesia, the infusion rate was decreased by $25 \%$ to $50 \%$ to maintain cardiovascuLar stability.
Cardiorespiratory variables; noninvasive blood pressure, heart rate, respiratory rate, and oxygen saturation were recorded 2 min after the loading dose and then every $5 \mathrm{~min}$ until the end of the ESWL procedure. Intraoperative side effects, including patient movement, complaints of pain and episodes of desaturation were recorded. The overall quality of the anesthetic state (smoothness, cardiovascular stability, absence of agitation, and or spontaneous motor activity) was assessed by the anesthesiologist monitoring the patients. Changes in hemodynamics values of $30 \%$ or more from the baseline state on three consecutive measurements every 1 min were considered signicant.

At the end of the procedure, the urologist and the anesthetist caring for the patient were asked to evaluate the adequacy of sedation, with a 5 . point scale ranging from awake and oriented to unarousable (table 1) [7], and analgesia using a three points scale $(0=$ good, $1=$ sufficient discomfort or pain but easily tolerable, $2=$ insufficient - discomfort or pain, requiring top up dose).

Patients were discharged from the post-anesthetic care unit when their vi-

MANSOURA MEDICAL JOURNAL 
tal signs were stable, they were able to walk, and they didn't experience persistent nausea, vomiting, or dizziness.

Statistical analysis of intergroup differences concerning the hemodynamic parameters was conducted using Mann Whitney $U$ test. $P$ values less than 0.05 was considered to be statistically significant.

\section{RESULTS}

The two study groups were comparable with respect to demographic data table (2). Midazolam premedication $2.5 \pm 6.0 \mathrm{mg}$ and ESWL time $29 \pm$ $9 \mathrm{~min}$ were also identical for both groups. There were no differences in the number and voltage of the shock waves given to each group (3000 shocks/session with 18 to $22 \mathrm{KV}$ ). Intraoperatively, the ketamine group required significantly more midazolam to control restlessness than did the fentanyl group (ketamine $1.8 \pm 2.2 \mathrm{mg}$ versus fentanyl $0.6 \pm 0.9 \mathrm{mg}$ ). The perioperative hemodynamic variables are summarized in tables (3,4 and 5). Ketamine group had significantly higher systolic and diastolic blood pessure values throughout the ESWL procedure; however, heart rate was significantly higher in the ketamine group at 2, 5 min after the loading dose. The ketamine group had also higher respiratory rate throughout the procedure (Fig. 1). Fentanyl group showed the highest incidence of respiratory upsets ( 5 patients) compared with ketamine group (one patient). Respiratory upsets were in the form of short periods of apnea that was relieved by manual support of the lower jaw. Figure 2 shows that $\mathrm{SpO}_{2}$ values were consistently higher in ketamine group throughout the ESWL procedure than fentanyl group. The number of episodes of $\mathrm{SpO}_{2}$ less than $90 \%$ was significantly higher in the fentanyl group. Intraoperative involuntary movements were exerted in 4 patients in ketamine group and no patient in fentanyl group, nausea and vomiting were reported in one patient in ketamine group and one patient in fentanyl group table (6). Evaluations of the intraoperative conditions (e.g. purposeful movements, cardiovascular changes or respiratory depression) revealed that the use of ketamine was associated with superior hemodynamic and respiratory stability. However ketamine produced more disruptive movement and longer recovery times ( $56 \pm 22 \mathrm{~min}$ versus $40 \pm 20 \mathrm{~min}$ ). The intraoperative pain scores as assessed at the completion of treatment 
and immediate postoperative period were listed in table (7). Finally patient satisfaction was high in both groups and the urologist rated the operating condition as excellent, sedation was mild and patients were easily arousable and able to communicate with the physicians during the procedure.

Incidence of common postoperative side effects (nausea, vomiting, dizziness, and confusion) did not differ significantly between the two groups.

Table 1: Sedation scale

\begin{tabular}{|l|l|}
\hline \multicolumn{1}{|c|}{ score } & \multicolumn{1}{|c|}{ Description of sedation } \\
\hline 1 & Fully awake and oriented \\
2 & Drowsy \\
4 & Eye closed but arousable to verbal commands \\
5 & Eye closed but arousable to mild physical stimulation \\
\hline
\end{tabular}

Table 2 : Patient data, values ar e mean $\pm S D$ and (range)

\begin{tabular}{|l|c|c|}
\hline & $\begin{array}{c}\text { Ketamine } \\
\text { group } \\
\mathrm{N}=20\end{array}$ & $\begin{array}{c}\text { Fentanyl } \\
\text { group } \\
\mathrm{N}=20\end{array}$ \\
\hline Male/female & $8 / 12$ & $11 / 9$ \\
Age & $46 \pm 12$ & $48 \pm 14$ \\
Height $(\mathrm{cm})$ & $166 \pm 8.9$ & $169 \pm 9.4$ \\
& $(155-180)$ & $(155-185)$ \\
Weight $(\mathrm{kg})$ & $71 \pm 12.1$ & $74.3 \pm 11.2$ \\
& $(43-95)$ & $(51-104)$ \\
\hline
\end{tabular}


Table (3) : Heart rate recorded (beats/ $\mathrm{min}$ ) before and during ESWL procedure in the two studied groups. Values are in median.

\begin{tabular}{|l|c|c|}
\hline & $\begin{array}{c}\text { Ketamine } \\
\text { group } \\
\mathrm{N}=20\end{array}$ & $\begin{array}{c}\text { Fentanyl } \\
\text { group } \\
\mathrm{N}=20\end{array}$ \\
\hline Basal & 92 & 94 \\
During ESWL: & $100^{*}$ & $62^{*}$ \\
$2 \mathrm{~min}$ & $115^{*}$ & $65^{*}$ \\
$5 \mathrm{~min}$ & 108 & 72 \\
$10 \mathrm{~min}$ & 99 & 79 \\
$15 \mathrm{~min}$ & 99 & 82 \\
$20 \mathrm{minm}$ & 98 & 82 \\
At the end of procedure : & 98 \\
\hline
\end{tabular}

* Significant difference between the two groups $(p<0.05)$.

Table (4) : Systolic blood pressure $(\mathrm{mm} \mathrm{Hg})$ measured before and during ESWL procedure in the two studied groups. Values are in median.

\begin{tabular}{|l|c|c|}
\hline & $\begin{array}{c}\text { Ketamine } \\
\text { group } \\
\mathbf{N}=20\end{array}$ & $\begin{array}{c}\text { Fentanyl } \\
\text { group } \\
\mathbf{N}=20\end{array}$ \\
\hline Basal & 131 & 132 \\
During ESWL: & $143^{*}$ & 127 \\
$2 \mathrm{~min}$ & $150^{*}$ & 132 \\
$5 \mathrm{~min}$ & $158^{*}$ & 125 \\
$10 \mathrm{~min}$ & $154^{*}$ & 128 \\
$15 \mathrm{~min}$ & $143^{*}$ & 132 \\
$20 \mathrm{minm}$ & $143^{*}$ & 132 \\
At the end of procedure : & \\
\hline
\end{tabular}

*Significant difference between the two groups $(p<0.05)$. 
Table (5) : Diastolic blood pressure $(\mathrm{mm} \mathrm{Hg})$ measured before and during ESWL procedure in the two groups. Values are in median.

\begin{tabular}{|l|c|c|}
\hline & $\begin{array}{c}\text { Ketamine } \\
\text { group } \\
\mathrm{N}=20\end{array}$ & $\begin{array}{c}\text { Fentanyl } \\
\text { group } \\
\mathrm{N}=20\end{array}$ \\
\hline Basal & 82 & 80 \\
During ESWL: & $97^{*}$ & 85 \\
$2 \mathrm{~min}$ & $102^{*}$ & 88 \\
$5 \mathrm{~min}$ & $106^{*}$ & 90 \\
$10 \mathrm{~min}$ & $106^{*}$ & 90 \\
$15 \mathrm{~min}$ & $106^{*}$ & 89 \\
$20 \mathrm{minm}$ & 102 & 88 \\
At the end of procedure : & 102 \\
\hline
\end{tabular}

Significant difference between the two groups $(p<0.05)$.

Table (6) : Number of patients developed intraoperative side effects during ESWL.

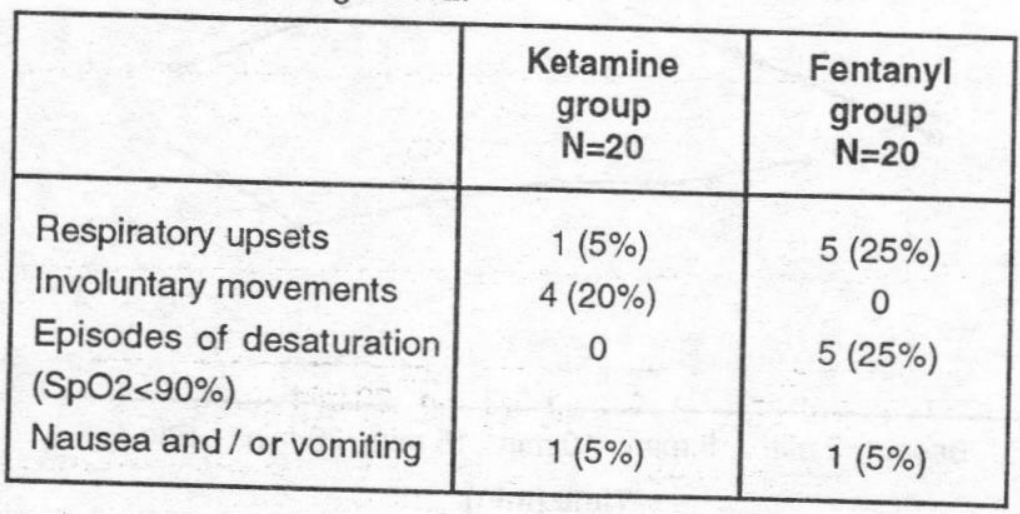


Table (7) : Intraoperative pain scores.

\begin{tabular}{|l|c|c|}
\hline & $\begin{array}{c}\text { Ketamine } \\
\text { group } \\
\mathbf{N}=20\end{array}$ & $\begin{array}{c}\text { Fentanyl } \\
\text { group } \\
\mathbf{N}=20\end{array}$ \\
\hline At conclusion of procedure : & & \\
0 & 14 & 12 \\
1 & 2 & 4 \\
2 & 4 & 4 \\
\hline At post operative : & & \\
0 & 16 & 14 \\
$\mathbf{1}$ & 4 & 4 \\
2 & 0 & 2 \\
\hline
\end{tabular}

$0=$ good

$1=$ sufficient - discomfort or pain, but easily tolerable.

2 = insufficient - discomfort or pain, requiring top up dose.

There were no significant differences.

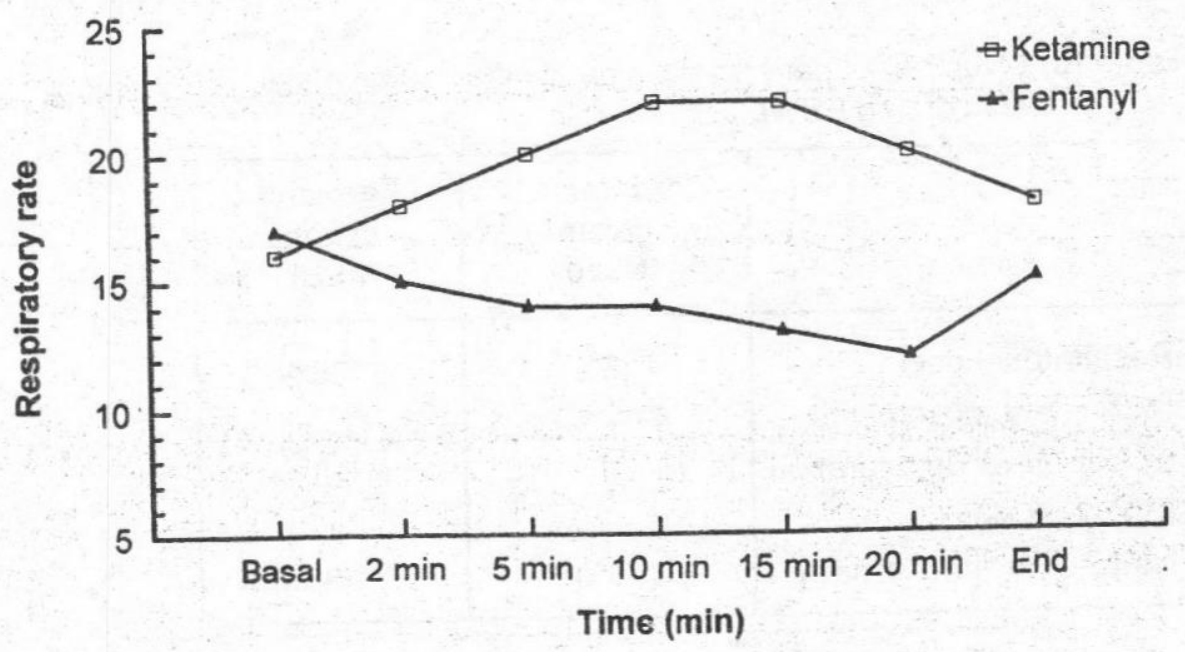

Fig. 1:

Vol. 30 , No. 1 \& 2 Jan. \& April, 2000 


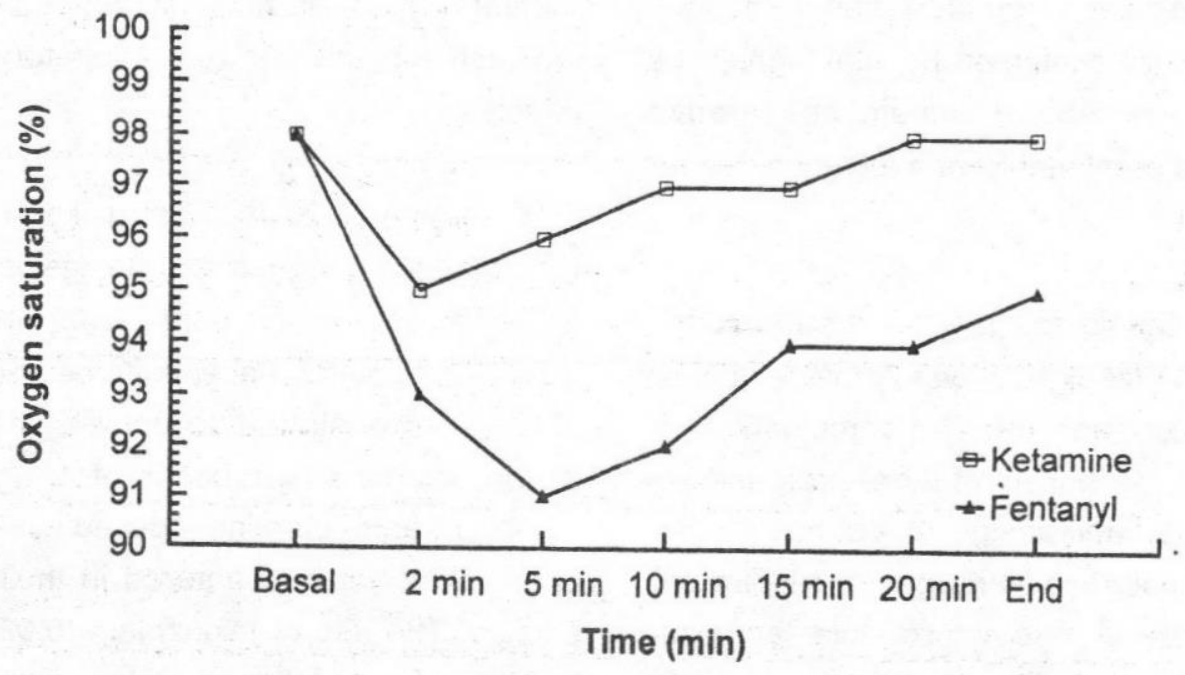

Fig. 2 :

\section{DISCUSSION}

Monitored Anesthesia Care (MAC) is being increasingly used in the 1990 s for a wide variety of diagnostic and therapeutic procedures. The primary objective in providing MAC is to ensure patient comfort and safety. However, more diagnostic and therapeutic rocedures are performed in locations remote from the operating suite. Anesthesiologists are often consulted for sedation and monitoring of these patients. Since introduction of ESWL at Mansoura Urology and Nephrology Center, monitored anes- thesia care has become the technique of choice for iithotripsy. It has provided effective analgesia in the 40 cases in which it has been used, as fentanyl and ketamine can be rapidly titrated to patient response. However, simplified anesthetic techniques are acceptable only if they do not require modification of the surgical technique or contribute to a suboptimal surgical outcome. Both of the two IV sedative analgesic techniques evaluated allowed the maximal number of shock waves and energy leve!s during ESWL procedures. The usual end MANSOURA MEDICAL JOURNAL 
point for titration of sedative anxiolytic drugs is the patient's verbal acknowledgment of comfort and relaxation usually confirmed by vital signs. The patient should remain cooperative and comfortable with airway reflex intact.

Opioid analgesics are often added to benzodiazepines to provide optimal patient comfort. The combination offers the benefit of more profound sedation and analgesia, but has the potential disadvantage of respiratory depression so hypoxaemia can occur during monitored anesthesia care $(8,9)$ From the results of the study we found that the use of midazolam - fentanyl combinations resulted in transient respiratory depression and hemoglobin oxygen desaturation (< $90 \%)$. Bailey and his colleagues (10) compared midazolam ( $0.05 \mathrm{mg} . \mathrm{kg} \mathrm{-1})$ or fentanyl ( $0.2 \mathrm{ug} . \mathrm{kg}-1)$ to a midazolam-fentanyl combination, the incidence of hypoxaemia and apnea was significantly increased when the two drugs were combined as fentayl 2. 0 ug kg - 1 produced hypoxaemia $\mathrm{SaO}_{2}$ $<90 \%$ ) in $50 \%$ of a group of healthy volunteers, and the addition of midazolam $0.05 \mathrm{mg} \mathrm{kg} \mathrm{-1}$ increased this incidence to $92 \%$ and resulted in half of the subjects becoming apneic for at least 15 seconds. So, careful titration of these drugs and the use of supplemental oxygen as nasal prongs can diminish the undesirable respiratory effects.

Ketamine $(0.25$ to $0.5 \mathrm{mg} . \mathrm{kg}-1$ IV) produces sedation and analgesia without respiratory depression in adults. In pediatric patients, Green et al. (11) demonstrated acceptable sedation with ketamine doses of $4 \mathrm{mg}$ $. \mathrm{kg}-1 \mathrm{i} . \mathrm{m}$ and ketamine induced dysphoria was not encountered in their studies. The use of midazolam ( 0.05 to $0.1 \mathrm{mg} \mathrm{kg} \mathrm{-1}$ ) followed by ketamine ( 0.25 to $0.5 \mathrm{mg} \mathrm{kg}-1 \mathrm{iv}$ ) produced excellent sedation, amnesia and analgesia during injection of local anesthetic solutions in adults undergoing plastic surgery (12) The use of ketamine and midazolam doesn't produce the same degree of ventilatory depression seen with a ben zodiazepine - opioid combination.

The use of ketamine for maintenance of analgesia was associated with fewer episodes of intraoperative oxygen desaturation and higher respiratory rates throughout the ESWL procedure. The sympathomimetic actions associated with ketamine administration also maintained intraopera- 
tive blood pressure at a higher level than the fentanyl group .So, ketamine was superior to fentanyl with respect to intraoperative cardiorespiratory stability.

Kennedy and his colleagues (13) compared the safety and efficacy of fentanyl/midazolam versus ketamine/ midazolam for pediatric orthopedic emergencies and reported that keta$\mathrm{mine} /$ midazolam is more effective for pain and anxiety relief than fentanyl/ midazolam. Furthermore, the respiratory complications are less frequent with ketamine/midazolam and respiratory support is more needed with fentanyl/midazolam.

The age and physical status of the patient are useful guides in evaluating organ system reserves and in determining their sensitivity to the sedative analgesic drugs commonly used during monitored anesthesia care (14). Patient positioning and anticipation of the physiologic impact of postural changes as well as prevention of nerve damage due to pressure are crucial (15). Although safe positioning can be ensured by maintaining contact with the patient, the administration of sedative and analgesic drugs may obscure progressive discomfort, so it is important to the anesthetist to check the patients position before and at least once during the procedure.

In conclusion, as extracorporeal shock wave lithotripsy (ESWL) is frequently carried out on an outpatient basis, it is crucial to choose an adequate analgesic with less adverse effect. The uniqueness of the patient environment is an anesthetic challenge and sedation - analgesia with ketamine combined with midazolam appears to be safe and effective with superior intraoperative cardiorespirtory stability. Furthermore, the need for stronger analgesia during larger voltage intensity should be tailored to the needs of the individuals. The success and safety of the MAC technique is probably more dependent on the skill of the anesthesia provider an the drug selection itself.

\section{REFERENCES}

Charig CR, Webb DR, Payne SR, Wickham JEA. (1986) : Comparison of treatment of renal calculi by open surgery, percutaneous and extracorporeal shock wave lithotripsy. $\mathrm{Br}$ Med $\mathrm{J}$, 292:879-82. 
Drach GW, Dretler S, Fair W, Finlayson B, Gillenwater J, Griffith D, Lingeman J, Newman D. (1986) : Report of the United States cooperative study of extracorpeal shock wave lithotripsy, J Urol, 135:1127-33

Duvall JO, Griffith DP. (1985) : Epidural anesthesia for extracorpeal shock wave lithotripsy. Anesth Analg. 64:544-6.

Fredich JD, Brull SJ, Schiff S. (1990) : Anesthesia for lithotripsy: Efficacy of monitored anesthesia care with alfentanil. Anesth Analg, 70:S115.

Weniniger E, Nyga B, Sachs M, Heidec, Mersted K, Riegler N, Feller S, Stoschek M, Peter K. (1996) : A comparative study of intravenous opioid analgesia. Sufentanil and alfentanil for extracorporeal shock-wave lithotripsy in urologic patients. Anaesthetist, 45:4t 330-6.

White PF, Way WL, Trevor AJ. (1982) : Ketamine: It's phar- macology and therapeutic uses. Anesthesiology, 56:119-36.

Wilson E, David A, Mackenzie N, Grant IS. (1990) : Sedation during spinal anaesthesia: comparison of propofol and midazolam. $\mathrm{Br} \mathrm{J}$ Anaesth, 64:48-52

Ghouri AF, Taylor E, White PF. (1992) : Patients controlled drug administration during local anesthesia: a comparison of midazolam, propofol and fentanyl. J Clin Anesth, $4: 476$.

Alexander CM, Gross JB. (1988) : Sedative doses of midazolam depress hypoxic ventilatory responses in humans. Anesth Anaig, 67:377.

Bailey PL, Pace NL, Ashburn MA, Moll JWB, East KA, Stanley TH. (1990) : Frequent hypoxemia and apnea after sedation with midazolam and fentany l. Anesthesiology, 73:826-30.

Green SM, Nakamura R, Johnson 
NE. (1990) : Ketamine sedation for pediatric procedures. Part 1. A prospective series. Ann Emerg Med, 19:1024.

White PF, Vasconez LO, Mathes SA et al. (1988) : Comparison of midazolam and diazepam for sedation during plastic surgery. Plast Reconstr Surg, 81:703.

Kennedy RM, Porter FL, Miller JP, Jaffe DM. (1998) : Comparison of fentanyl $/$ midazolam with ketamine/midazolam for pediatric orthopedic emergencies. Pediatrics, 102:4 Pt 1, 956-63.

White PF. (1986) : Anesthetic techniques for the elderly outpatient. Int Anesth Clin, 26:105.

Wilcox S, Vandam LD. (1988) : Alas, poor Trendlenberg and his position! A critique of its uses and effectiveness. Anesth Analg, 67:574. 
